\title{
Effect of Processing Conditions in the Preparation of PP-Ternary Nanocomposite Using MWCNT as Secondary Filler
}

\author{
Salawudeen Taofeeq Olalekan ${ }^{1}$, Maan F. Alkathib ${ }^{1}$, Faridah Yusof ${ }^{1}$, Qasim H. Shah ${ }^{2}$ and Suleyman A. Muyibi ${ }^{1}$ \\ 1. Department of Biotechnology Engineering, Faculty of Engineering, International Islamic University Malaysia, Kuala Lumpur \\ 50728, Malaysia
}

2. Department of Mechanical Engineering, International Islamic University Malaysia, Kuala Lumpur 50728, Malaysia

Received: August 02, 2010 / Accepted: August 24, 2010 / Published: February 10, 2011.

\begin{abstract}
The present paper investigates the behavior of experimental polypropylene ternary nanocomposites produced in the laboratory under different process conditions using multiwall carbon nanotube as secondary filler. Full factorial experimental design was explored to study the effect of temperature, mixing speed and carbon nanotube (CNT) loading on the morphological and mechanical features of the ternary nanocomposites following the determination of maleic anhydride grafted polypropylene (MAgPP) percentage required for the intermediate composite. Tensile properties and morphological characterization were studied using universal tensile machine (UTM) and scanning elecrtron microscope (SEM) machines respectively. The results revealed that process temperature and CNT loading influences both the morphological and mechanical properties of polypropylene ternary nanocomposites, whereas, the mixing speed has little effect on these properties. Specifically, CNT loading in amount less than $1 \%$ showed better tensile strength and stiffness while the strength falls off at $1 \%$ CNT loading. Morphological studies indicate better dispersion of CNT in the binary composite system at process temperature of $170{ }^{\circ} \mathrm{C}$ and formation of agglomerates at $250{ }^{\circ} \mathrm{C}$. The present study suggests that $\mathrm{CNT}$ loading and process temperature lower than $1 \%$ and $200{ }^{\circ} \mathrm{C}$ respectively produces polypropylene ternary nanocomposites with better mechanical properties and enhanced dispersion of the CNT in the composite system at a moderate mixing speed slightly above 100 rpm.
\end{abstract}

Key words: CNT, process conditions, tensile properties, ternary nanocomposites.

\section{Introduction}

Polypropylene is a commodity polymer, which offers probably the best price and performance properties among polyolefins [1]. It has a wider area of applications such as packaging, home utensils, casings and automobile accessories when compared to any other thermoplastic. In addition, polypropylene has a lower density [between (900-920) $\left.\mathrm{kg} / \mathrm{m}^{3}\right]$, in comparison to other engineering materials, allowing for potential weight

Corresponding author: Salawudeen Taofeeq Olalekan (1969- ), male, research student, research field: nanotechnology (polymer composite). E-mail: salawusalawu@yahoo.co.uk. reductions [2], very good heat resistance and due to its higher crystallinity, has excellent moisture barrier and good optical properties [1].

Polymers in their pure and natural state are reinforced with organic fillers such as sisal, flax, jute and wood fibres [3]. Such polymer composite are credited with better properties relative to their parent matrix. These natural fibres reinforced composites find a wide array of applications in the civil construction industries. They are term microcomposite because the fillers are dispersed in micro scale.

Polymer nanocomposites production became subject of interest since the successful preparation and application of $\mathrm{PA} /$ montmorillonite composites by 
Toyota et al. [4] over a decade ago. Since then organically modified layered silicates have been widely studied as property enhancers for polymeric materials [5]. Various studies have reported improvement in mechanical [6-8], thermal and flammability $[9,10]$, and barrier [11, 12] properties of thermoplastic by addition of organically modified layered silicates to polymer matrices. The nanocomposite prepared from PA 6 by Toyota group however, possessed good mechanical and thermal properties at very low filler loading and therefore providing a better economical solution in various fields of application [4].

Polypropylene, among thermoplastic, has a wider area of industrial applications and these has caused the polymer to be widely studied. It can be modified in many ways and its fibre reinforced grades compete even with most engineering polymers. As a consequence, many attempts have been made to prepare polypropylene-layered silicate nanocomposite in order to have a material of better properties compared to the conventional polymer microcomposite. However, practically all composites prepared from organophilic clay and a PP homo- or copolymer do not show improvements in an extents to satisfy the requirements of most applications and justify their use [13]. In addition, the achieved properties usually involve a lot of trade off, the stiffness traded for toughness or toughness is obtained at cost of elongation which indirectly affects the flexural strength. As a result, effort is ongoing to produce a composite that will combine more than one filler in a polymer matrix. Such that there will be property sharing and shortcomings from one filler can be addressed by the other called secondary filler.

The main goal of the present work is to investigate the production of PP nanocomposites using layered silicates and multiwall carbon nanotubes as fillers and to establish the operating conditions under which such smart material could be produced. Effort was also made to study the distribution of both the primary filler (layer silicate) and the secondary filler multi wall carbon nanotube (MWCNT) in the matrix by using the appropriate equipment in order to compare the effect of the particle distribution with mechanical properties enhancement.

\section{Experiment}

The organoclay (MNC) used for the preparation of the nanocomposites was supplied by Sigma Aldrich. The maleic anhydride grafted polypropylene (MAgPP) used was Polybond 3200 with $1 \%$ wt, manufactured by Uniroyal chemical. Polypropylene homopolymer manufactured by Polypropylene Malaysia Sdn was used as matrix. Finally, the multiwall carbon nanotubes manufactured by Zyvex Instrument, Germany was supplied by Cahaya Bhd SDN, Malaysia. All the above materials were used as received.

\subsection{Preparation of Polypropylene Ternary Nano-composites}

Experimental design was adopted using design expert version 6.0.8, Statease Inc, USA with full factorial, three factors (temperature $(\mathrm{M} / \mathrm{T})$, mixing speed (M/S) and CNT loading), and responses (Tensile strength and Young's modulus). The design output is as shown in Table 1.

Ternary nanocomposite production was effected by using 3\% layered silicate (MNC) for the preparation of the intermediate product ( $\mathrm{PP} / \mathrm{MNC}$ nanocomposite) [14] while the required percentage of MAgPP was determined experimentally [15].

Table 1 Experimental design using full factorial.

\begin{tabular}{|c|c|c|c|c|}
\hline Std & Run & CNT (\%) & $\mathrm{M} / \mathrm{S}$ (rpm) & M/T. $\left({ }^{\circ} \mathrm{C}\right)$ Responses: \\
\hline 7 & 1 & 0.1 & 200 & 250 \\
\hline 1 & 2 & 0.1 & 100 & 170 \\
\hline 2 & 3 & 1 & 100 & 170 \\
\hline 6 & 4 & 1 & 100 & 250 \\
\hline 3 & 5 & 0.1 & 200 & 170 \\
\hline 4 & 6 & 1 & 200 & 170 \\
\hline 5 & 7 & 0.1 & 100 & 250 \\
\hline 8 & 8 & 1 & 200 & 250 \\
\hline
\end{tabular}




\subsection{Determination of Best Percentage MAgPP Required for Polypropylene Compatibility}

Success in the production of PP ternary nanocomposite depends on the degree of dispersion of clay in the matrix prior to the introduction of multiwall carbon nanotubes. Chemical coupling agents such as MAgPP are usually added to enhance interfacial adhesion between the filler and polymer matrix. However, too low maleic-anhydride (MAH) content does not promote nanocomposite formation while too high MAH content made the master batch so robust and prevent further mixing of $\mathrm{MNC}$ and $\mathrm{PP}$ and hence prevent good dispersion [16]. Effort must therefore be made to know the exact MAgPP required for the production of the intermediate composite.

$\mathrm{PP} /$ clay intermediate composites were compounded on haake mixer (Type: Rheomix 600P) at $170{ }^{\circ} \mathrm{C}$ melting temperature, $125 \mathrm{rpm}$ mixing speed for $12 \mathrm{~min}$. The percentage clay was kept at $3 \%$ while the compatibilizer varied between $5 \%$ and $30 \%$ of the entire batch. The entire mixture was mixed until homogeneity was attained after $12 \mathrm{~min}$ and the final products was dropped down and pelletized. The nanocomposite pellets were hot pressed cut to the standard shape and analyzed for tensile properties using ASTM D638 Type IV. The MAgPP\% of the plaque with best tensile properties was taken as the percentage of MAgPP required for the preparation of intermediate composite.

\subsection{Dispersion of Multiwall Carbon Nanotubes (MWCNT) in the Intermediate Composite}

MWCNTs were dispersed in the intermediate composite using the prescribed quantity following the experimental design (Table 1). The entire mixture was allowed to mix for a period of $10 \mathrm{~min}$ before homogeneity was attained. The MWCNTs percentage was randomized between $0.1 \%$ and $1 \%$ of $\mathrm{PP} /$ clay composite. The nanocomposite was manually pelletized, hot pressed and molded into dumbbell shape according to ASTM D368. The molded plaques were then subjected to test mechanical using universal tensile machine (UTM) and the results compared.

\section{Results and Discussion}

\subsection{Effect of MAgPP Content on the Tensile Properties of Intermediate Composite}

Due to apolar nature of polypropylene, it is almost impossible to get organically modified clay disperse in the matrix [17]. Manias et al. [16] reported that MAgPP pretreatment with very high MAH content does not promote good dispersion and if too low affect the properties of the final nanocomposites. This has prompted the determination of the appropriate percentage of MAgPP required for the dispersion of layered silicate in PP-matrix.

Fig. 1 shows the behavior of the tensile properties relative to increase in MAgPP content in the $\mathrm{PP} /$ clay intermediate composite. At $0 \% \mathrm{MAgPP}$ in the absence of modified nanoclay, the properties of the virgin PP was $33.38 \mathrm{MPa}$ and $1085.76 \mathrm{MPa}$ for tensile strength and Young modulus respectively. There was a slight reduction in the properties of $\mathrm{PP} /$ clay nanocomposite due to the addition of 5\% MAgPP. This is characteristics of MAgPP once the optimal condition is not attained in the PP/clay composite. The same explanation holds for MAgPP above 9\%. However, a point exist in the graph (P), which conformed with $9 \%$ $\mathrm{MAgPP}$, here, there was an appreciable enhancement

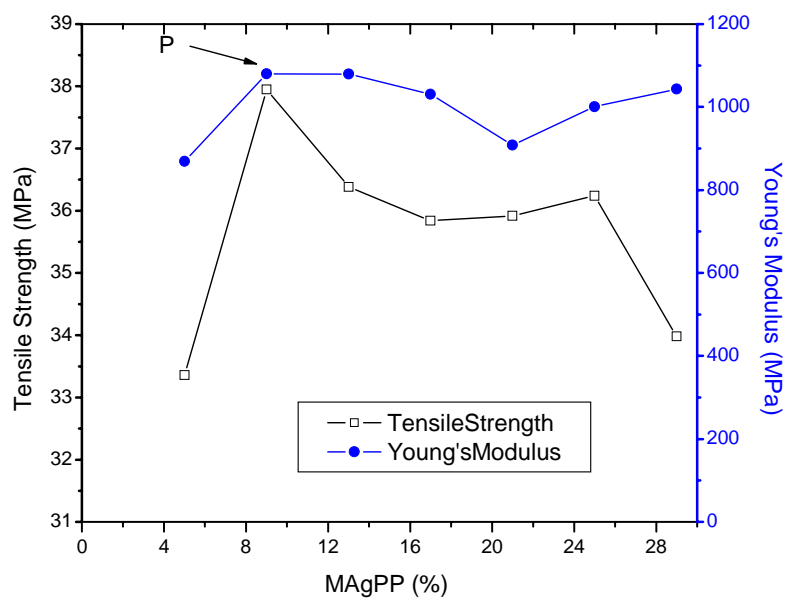

Fig. 1 Effect of MAgPP on the mechanical properties of PP/clay intermediate composite. 
in the tensile strength of the composite which corresponds to $13.69 \%$ while there was a slight reduction in the Young modulus $(<0.5 \%)$. Above $9 \%$ however, there was a sharp reduction in both properties. It can be inferred from the above that point $\mathrm{P}(9 \%$ MAgPP) which gave 37.9 MPa for tensile strength and 1080.14 MPa for Young modulus correspond to the best percentage of MAgPP required for the preparation of the intermediate master batch.

\subsection{Effect of MWCNT Loadings on the Tensile} Properties of Ternary Nanocomposite under Different Process Conditions

One of the important properties use in characterizing the strength of material is tensile strength and the Young's modulus [18]. These two properties are used in this work to screen the range of the selected operating parameters (temperature, mixing speed and CNT loading). The samples were labeled $\mathrm{A}$ to $\mathrm{H}$ according to the numbers of runs.

Table 2 shows the tensile properties dependence of the selected process parameters using single factor screening. This consideration would forecast the effect of low and high value of the selected operating parameters on the tensile properties and hence give the range at which the ternary nanocomposite can be best produced. The results were analyzed by considering a pair of the samples with two similar process parameters for example (mix speed \& CNT loading) and the other parameter (temperature) varied at a time. The results show that at $250{ }^{\circ} \mathrm{C}$ melting temperature, there was a sharp difference in the tensile properties of the nanocomposites compared with the value at $170{ }^{\circ} \mathrm{C}$. The tensile properties at $170^{\circ} \mathrm{C}$ are in the range of 30 to $32 \mathrm{MPa}$ and 1600 to $1800 \mathrm{MPa}$ tensile strength and Young's modulus respectively while at $250{ }^{\circ} \mathrm{C}$, the properties lies in the range of 20 to $26 \mathrm{MPa}$ tensile strength and 1500 to $1700 \mathrm{MPa}$ Young's modulus respectively. The lost in the tensile properties at higher temperature could be traced to the degeneration in the plastic properties of PP which resulted to low viscosity and hence lost in binding effect on the fillers within the matrix. This agreed with the Eisten equation which states that effect of filler on modulus is proportional to that on viscosity and this is represented mathematically thus:

$$
\eta=\eta_{s}\left(1+2.5 V_{r}\right)
$$

Where $\eta$ represents the viscosity of the composite, $\eta_{s}$ represents the viscosity of the matrix and $V_{r}$ the filler volume fraction.

The viscosity terms in Eq.(1) above can be replaced by the modus term $\mathrm{E}$ as shown:

$$
E=E_{s}\left(1+2.5 V_{r}\right)
$$

where $E$ and $E_{S}$ represent the modulus for composite and matrix respectively.

Therefore, at $250{ }^{\circ} \mathrm{C}$ melting temperature, an irreversible drop in viscosity of the nanocomposites resulted in a drop in the stiffness measured in terms of the Young's modulus.

Similarly, when compared the percentage of MWCNT in each sample at a fixed value of other process conditions (temperature and mixing speed), the results show that at higher CNT loading $(\geq 1 \%)$ nanocomposites tend to lose the tensile properties. This is due to the formation of agglomerates within the matrix as a result of matrix saturation with the filler particles. Hence, the composite behave more like a microcomposite at a higher CNT content. Though the sheers may have effect on the mixing but the effect is not significant when the speed is kept within 170 and $200 \mathrm{rpm}$ as shown in Table 2 and therefore should be kept at minimum value.

\subsection{Morphological Characterization Using SEM}

SEM micrographs taken from the etched surfaces of $\mathrm{PP} /$ clay (sample O), $\mathrm{PP} /$ clay/CNT at $170{ }^{\circ} \mathrm{C}$ melting temperature and $200 \mathrm{rpm}$ mixing speed (sample $\mathrm{E}$ ) and $\mathrm{PP}-\mathrm{Clay} / \mathrm{CNT}$ at $250{ }^{\circ} \mathrm{C}$ melting temperature and 200 rpm mixing speed (sample G) nanocomposites are shown in Fig. 2.

Sample O (PP/clay) contained no CNTs and hence appeared smoother when compared to other two. This 
Table 2 Effect of process parameters and CNT loadings on the tensile properties of nanocomposites.

\begin{tabular}{llllll}
\hline Sample & Melt/Temp. $\left({ }^{\circ} \mathrm{C}\right)$ & Mix speed $(\mathrm{rpm})$ & CNTs Loading $(\%)$ & Ten/St $(\mathrm{MPa})$ & Young/Mod $(\mathrm{MPa})$ \\
\hline PP/clay & 180 & 125 & - & 31.16 & 1080.96 \\
PP/clay/CNTs & & \multicolumn{3}{l}{} \\
A & 250 & 200 & 0.1 & 25.1 & 1756.74 \\
E & 170 & 200 & 0.1 & 31.58 & 1604.53 \\
F & 250 & 100 & 0.1 & 26.11 & 1560.90 \\
H & 170 & 100 & 0.1 & 31.27 & 1629.56 \\
B & 170 & 100 & 1.0 & 29.55 & 1810.82 \\
D & 250 & 100 & 1.0 & 23.53 & 1632.09 \\
C & 170 & 200 & 1.0 & 31.15 & 1687.62 \\
G & 250 & 200 & 1.0 & 22.73 & 1640.20 \\
\hline
\end{tabular}

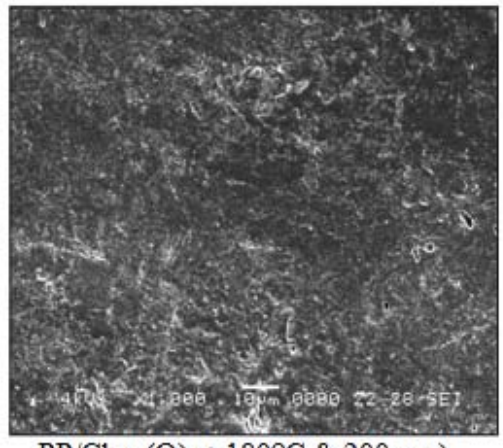

$\mathrm{PP} / \mathrm{Clay}(\mathrm{O})$ at $\left.180^{\circ} \mathrm{C} \& 200 \mathrm{rpm}\right)$

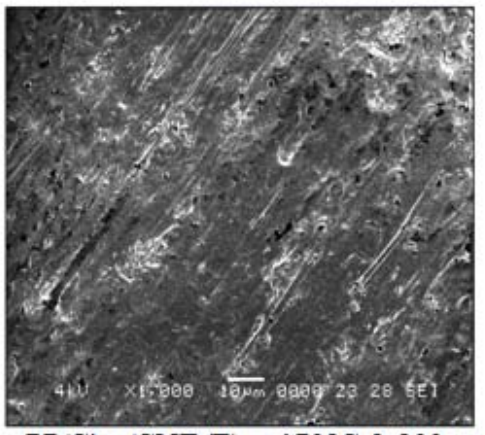

$\mathrm{PP} / \mathrm{Clay} / \mathrm{CNT}(\mathrm{E})$ at $170^{\circ} \mathrm{C} \& 200 \mathrm{rpm}$

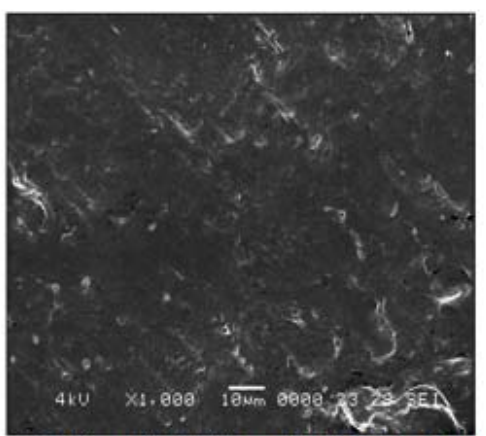

$\mathrm{PP} / \mathrm{Clay} / \mathrm{CNT}(\mathrm{G})$ at $250^{\circ} \mathrm{C} \& 200 \mathrm{rpm}$

Fig. 2 SEM images of the nanocomposites produced under different process conditions.

is an indication of uniform distribution of layered silicate in the PP-matrix. However, the distribution of carbon nanotubes in the binary system is obvious as seen in black patches in sample $\mathrm{E}$ and hence has better tensile properties when compared with sample $\mathrm{G}$ with even a higher percentage of CNTs (1\%). This is because at $250{ }^{\circ} \mathrm{C}$, PP tends to lose its viscosity and hence both the clay and CNT tends to form more agglomerates and the filler distribution is no longer uniform. It is therefore evident from the above images that uniform distribution of fillers can be best achieved at a moderate temperature and low filler loading.

\section{Conclusions}

Ternary nanocomposites have been prepared and the effect of processing conditions was investigated. It can be concluded that high temperature $\left(\mathrm{T}>170{ }^{\circ} \mathrm{C}\right)$ and CNT loadings $\geq 1 \%$ is not favorable for the production of polypropylene ternary composite that consist of both nanoclay and carbon nanotubes in the PP matrix when layered silicate is fixed at $3 \%$. The mixing speed did not have much effect on the properties at higher degrees and hence should be kept at a moderate value above $100 \mathrm{rpm}$.

\section{Acknowledgments}

The authors are grateful to the Malaysia ministry of higher education for funding this project under FRGS 0206-56.

\section{References}

[1] V. Mittal, Polypropylene-layered silicate nanocomposites: filler matrix interactions and mechanical properties, Journal of Thermoplastic Composite Materials 20 (2007) 575-599.

[2] L. Valentini, K. BiagiottI, J.M. Kenny, M. Lopez, M.A. Manchando, Physical and mechanical behaviour of single wall carbon nanotube/polypropylene/ethylene-polypropylene-diene rubber nanocomposite, J. Appl. Polym. Sci. 89 (2003) 2657-2663.

[3] N. Hu, Z. Masuda, G. Yamamoto, H. Fukunaga, T. Hashida, J. Qin, Effect of fabrication process on electrical properties of polymer/multi-wall carbon nanotube nanocomposites composites: Part A, Science Direct (2008) 893-903. 

Secondary Filler

[4] Y. Fukushima, A. Okada, M. Kawasumi, T. Kurauchi, O. Kamigaito, Swelling behavior of montmorillonite by poly-6-amide clay mineral, Journal of Clay Mineral 23 (1988) 27-34.

[5] A. Bafna, G. Beaucage, F. Mirabella, S. Mehta, 3D hierachical orientation in polymer-clay nanocomposite film, Polymer 44 (2003) 1103-1115.

[6] P.V. Joseph, J. Kuruvilla, T. Sabu, Effect of processing variables on the mechanical properties of sisal-fibre-reinforced polypropylene composites, Composite Science and Technology 59 (1999) 1625-1640.

[7] T.D. Fornes, P.J. Yoon, H. Keskkula, D.R. Paul, Nylon 6 nanocomposites: the effect of matrix molecular weight, Polymer 42 (2001) 9929-9940.

[8] A. Oya, Y. Kurokawa, H. Yasuda, Factors conrolling mechanical properties of clay mineral/polypropylene nanocomposites, J. Matter. Sci. 35-5 (2000) 1045-1050.

[9] G. Beyer, Flame retardancy of TPU and PVC nanocomposites gummi, Fersern Kunststoffe 59 (2006) 493-498.

[10] J.W. Gilman, Flamability and thermal stability studies of polymer layered-silicate (clay) nanocomposites, Applied Clay Science 15 (1999) 31-49.

[11] T.K. Chen, Y.I. Tien, K.H. Wei, Synthesis and characterization of novel segmented polyurethane/clay nanocomposit, Polymer 41 (2000) 1345-1353.
[12] R. Sudip, Y.Q. Siew, E. Allan, D.C. Xiao, The potential use of polymer-clay nanocomposites in food packaging, International Journal of Food Engineering 2 (2006) 1-11.

[13] S. Laszlo, A. Agnes, B. Pukanszky, J. Julius, B. Punkaszky, Morphorlogical characterization of PP/clay nanocomposites across the length scales of the structiral acchitectecture, Micromole. Matter. Eng. 291 (2006) 858-868.

[14] D. Garcia-Lopez, O. Picazo, J.C. Merino, J.M. Pastor, Polypropylene-clay nanocomposites: Effect of compatibililizing agents on clay dispersion, European Polymer Journal 39 (2003) 945-950.

[15] T.O. Salawudeen, A.M. Suleyman, H.S. Qasim, F.A. Maa'n, Y. Raridah, Y.Q. Isam, Improving the polypropylene-clay composite using carbon nanotubes as secondary filler, Energy Research Journal 1 (2010) 68-72.

[16] E. Manias, A. Touny, L. Wu, K. Strawhecker, B. Lu, T.C. Chung, Polypropylene/montmorillonite nanocomposites: review of the synthetic routes and materials properties, Chem. Mater. 13 (2001) 3516-3523.

[17] S. Dean, Y. Wai, K.Y. Robert, K. Zhuo, Y. Jinghua, An investigation on the dispersion of montmorillonite (MMT) primary particles in PP matrix, European Polymer Journal 43 (2007) 3250-3257.

[18] K. Meryer, Hand Book of Material Seledtion, First edition, John Willey and Sons Inc, New York, 2002, pp. 547-549. 